\title{
Gestão de Qualidade de Vida no Trabalho (QVT) no Serviço Público Federal: O Descompasso entre Problemas e Práticas Gerenciais ${ }^{1}$
}

\author{
Mário César Ferreira ${ }^{2}$ \\ Luciana Alves \\ Natalia Tostes \\ Universidade de Brasília
}

\begin{abstract}
RESUMO - Os programas de Qualidade de Vida no Trabalho (QVT) têm crescido significativamente nos últimos anos. Todavia, o perfil das práticas de QVT em órgãos públicos brasileiros permanece pouco explorado. A presente pesquisa objetivou caracterizar as práticas de QVT em 10 órgãos públicos federais. Realizou-se análise documental e entrevista semi-estruturada. Os dados foram tratados por análise de conteúdo, modalidade categorial temática. Os resultados mostram que as práticas de QVT se caracterizam por nítido descompasso entre problemas existentes e atividades realizadas, com uma abordagem de QVT de viés assistencialista, que tem no trabalhador a variável de ajuste. A análise dos dados fornece importantes elementos para uma agenda de trabalho, tanto acadêmica quanto organizacional, com uma abordagem de QVT de natureza preventiva.
\end{abstract}

Palavras-chave: qualidade de vida no trabalho; QVT; ergonomia da atividade; serviço público federal; gestão pública.

\section{Quality of Life at Work (QLW) Management in the Federal Public Service: The Unbalance between Problems and Managerial Practices}

\begin{abstract}
Programs of Quality of Life at Work (QLW) have been increasing significantly in the last years. However, the profile of QLW practices in Brazilian public organs remains little explored. This research aimed at characterizing the QLW practices in 10 federal public organs. A documental analysis and semi-structured interviews were performed. The data were treated by content analysis, thematic categorical modality. Results show that QLW practices are characterized by a clear unbalance between existing problems and activities done, with an assistencialist bias to the QLW approach, which considers the employee as the adjust variable. The data analysis provides important elements to build a work agenda, as academic as organizational, with a preventive nature of the QLW approach.
\end{abstract}

Keywords: quality of life at work; QLW; ergonomy of activity; federal public service; public management.

O objetivo central desta pesquisa consistiu em conhecer as práticas de Qualidade de Vida no Trabalho (QVT) em órgãos públicos federais. Se no setor privado a temática QVT tem historicamente maior inserção e presença, no setor público ela permanece uma questão incipiente e um campo científico de interesse ainda restrito (Ferreira, 2006a). Nesse sentido, é ilustrativo o rastreamento feito sobre QVT por LimongiFrança (2004) em organizações que praticam, publicam, fazem consultoria, discutem e pesquisam a temática, pois ela tem sido objeto de interesse crescente de dirigentes, gestores, trabalhadores, profissionais das ciências do trabalho e pesquisadores.

$\mathrm{O}$ primeiro aspecto que caracteriza tal interesse situa-se no contexto da história recente das formações socioeconômicas capitalistas. O interesse de empresários e gestores na QVT tem mais de meio século (Macedo, 2004; May, 1999). Entretanto, somente a partir da década de 1970, a QVT passou a ser um objeto de preocupação e de investimento, sobretudo, nas grandes corporações. Esse período histórico coloca em primeiro plano um traço importante do movimento corpo-

1 Trabalho realizado com apoio de Bolsa de Produtividade (CNPq) para o primeiro autor.

2 Endereço para correspondência: Colina UnB, Bloco J, apto 101. Brasília, DF. CEP 70.910-900.E-mail: mcesar@unb.br rativo em busca de se implantar Programas de Qualidade de Vida no Trabalho (PQVT): a crise estrutural nos padrões de acumulação taylor-fordista. Os limites sociais e técnicos do modelo de gestão capitalista impõem novas bases para a competitividade empresarial.

A década de referência da crise (1965-1975) se caracteriza por fatos importantes: radicalização e endurecimentos dos movimentos sindicais dos trabalhadores; descompasso entre valorização do capital e o aumento da produtividade; choque do aumento do preço do petróleo; ascensão das taxas de juros no início dos anos 70; redução de investimentos impactando nas taxas de emprego e renda. É nesse contexto que um processo de reestruturação produtiva se instaura, operando mudanças institucionais nas relações de produção e de trabalho e no papel dos estados nacionais (Baumgarten, 2002). No conjunto, as mudanças no cenário produtivo que se operam nas sociedades capitalistas ocidentais aparecem acompanhadas das seguintes características: redução do papel do Estado; políticas governamentais de valorização do capital financeiro; flexibilização dos contratos de trabalho; aumento crescente das taxas de desemprego e exclusão social; e baixa e instável expansão da riqueza para a sociedade como um todo.

Atualmente, a necessidade de PQVTs nas organizações aparece marcada por uma aceleração de mudanças 
no mundo do trabalho, com destaque para o ritmo intenso das inovações tecnológicas na sociedade da informação, o crescente conteúdo de conhecimento agregado à produção, a diminuição do ciclo de vida dos produtos e os processos de produção que mudam em alta velocidade. As denominadas "indústrias do conhecimento" crescem e demandam profissionais mais qualificados, exigindo que as habilidades tenham que ser atualizadas constantemente. Os "ventos da mudança", embalados pela globalização, varrem as organizações, buscando transformá-las em instituições mais eficientes e com quadro de pessoal reduzido. Assim, um processo de metamorfose das profissões tradicionais se instala, exigindo a especialização flexível (agregação de novas tarefas), a flexibilidade funcional (rodízio de atividades, polivalência, multiqualificação) e a politecnia (tarefas complexas, habilidade criativa). Do "novo trabalhador" espera-se o desenvolvimento de capacidades para manejar novas ferramentas tecnológicas, lidar com problemas menos estruturados, relacionar-se socialmente (comunicação, negociação, solução de conflitos), trabalhar em equipes, e assumir novas responsabilidades para atuar em ambientes com maior incerteza, papéis pouco definidos e equipamentos altamente sofisticados. Um novo paradigma organizacional vai, paulatinamente, se afirmando: não basta garantir a qualidade final de produtos e serviços; é vital que ela venha acompanhada de qualidade de vida no trabalho, considerando os colaboradores. Nessa perspectiva, na sua origem, a QVT é considerada uma evolução/ desenvolvimento/ expansão do enfoque Qualidade Total (Westley, 1979).

Do ponto de vista institucional, no caso da presente pesquisa nas organizações públicas, as mudanças que ocorrem no mundo do trabalho produzem impactos nos aparelhos de Estado, colocando na agenda das inovações novos desafios relativos ao papel dos órgãos públicos, suas finalidades, suas estruturas e o seu próprio funcionamento. Esse processo se desenrola em um contexto de consolidação de direitos e valores democráticos, colocando em cena novos atores sociais que forjam uma nova cidadania. Ademais, corolário das metamorfoses que se operam no mundo do trabalho, a literatura científica veicula resultados que mostram os efeitos negativos de um processo de modernização conservadora que tem feito aumentar os índices de absenteísmo, de acidentes, das doenças do trabalho e de licenças-saúde nas organizações públicas (Tuuli \& Karisalmi, 1999). Historicamente, tais efeitos parecem mostrar que, em essência, os modelos de gestão do trabalho não se alteraram radicalmente no contexto da reestruturação produtiva.

É com base nesse macrocenário sociotécnico de mudanças que se inscreve a necessidade de gestores em repensarem as práticas organizacionais, buscando responder eficientemente às exigências da nova conjuntura. Esse "novo fazer" pressupõe reestruturar o "pensar" e o "saber" que guiam a atuação dos gestores, sobretudo, porque o processo de transformação que ocorre no mundo do trabalho não é neutro para aqueles que o vivenciam. Nessa perspectiva, o bem-estar dos servidores públicos, a satisfação do usuário-cidadão, a eficiência e a eficácia dos serviços prestados pelos órgãos governamentais constituem desafios inerentes às práticas de gestão, voltadas para a promoção da QVT.
Do ponto de vista acadêmico, a QVT (e suas variantes estrangeiras Quatility of Life at Work, Qualité de Vie au Travail, Calidad de Vida Laboral) tem sido objeto de interesse crescente de pesquisadores que atuam no campo das ciências do trabalho. Embora, como dito antes, a preocupação com o tema tenha mais de meio século, só nos últimos 30 anos constata-se um crescimento de estudos e, em consequência, formulações teóricas e metodológicas mais consistentes. Historicamente, a QVT tem sido abordada com base em diferentes perspectivas analíticas expressas por distinções com base em pressupostos norteadores, visão de ser humano, concepção de trabalho, diversidade de indicadores e enfoques de gestão.

Os autores de referência em QVT, largamente citados na literatura científica, são Walton (1973) e Hackman e Oldham (1975). Eles podem ser considerados os precursores de uma abordagem científica de QVT, embora aspectos importantes de suas formulações mereçam uma análise crítica mais aprofundada (e.g., concepção de ser humano, subjacente aos enfoques). Para Walton, a QVT depende estreitamente do equilíbrio entre trabalho e outras esferas da vida, do papel social da organização e da importância de se conciliar produtividade com QVT. O modelo proposto pelo autor contempla os seguintes fatores: compensação justa e adequada; condições de trabalho; uso e desenvolvimento das capacidades; chances de crescimento e segurança; integração social na empresa; constitucionalismo; trabalho e espaço total de vida e relevância social do trabalho. Na ótica de Hackman e Oldham, a QVT está fortemente associada aos aspectos de motivação interna, satisfação no cargo e enriquecimento do cargo. Nessa perspectiva, a gestão de QVT deve basear-se nos seguintes fatores: na força de necessidade de crescimento do trabalhador; percepção do significado da tarefa (variedade de habilidades, identidade da tarefa), significado da tarefa, autonomia e tarefa.

Do ponto de vista das organizações, a importância do tema QVT se inscreve numa perspectiva de enfrentamento dos problemas presentes no cotidiano dos ambientes de trabalho que colocam a qualidade de vida no trabalho como uma real necessidade (Laschinger, Finegan, Shamian \& Almost, 2001; Martel \& Dupuis, 2006; Sirgy, Efraty, Siegel \& Lee, 2001). O interesse pela mensuração de variáveis que compõem a temática QVT vem crescendo (Lau, 2000). No Brasil, sobretudo nos anos 90 do século passado, tem crescido a produção científica sobre o tema, com destaque para a Administração e a Psicologia. As publicações em QVT têm enfatizado diferentes aspectos: conciliação dos interesses das organizações e dos indivíduos (Fernandes, 1996); saúde, estilo de vida e ambientes de trabalho (Silva \& Marchi, 1997); segurança e higiene no trabalho (Signorini, 1999); conflitos decorrentes das relações interpessoais (Bom Sucesso, 2002); escolas de pensamento, indicadores empresariais (biológicos, psicológicos, sociais e organizacionais) e os fatores críticos de gestão (LimongiFrança, 2004); saúde mental, condições, organização e relações de trabalho (Sampaio, 2004). Mas, em que medida tais contribuições têm efetivamente influenciado as práticas de gestão da QVT em organizações públicas e privadas? Essa é uma questão que permanece em aberto. 
A análise e interpretação dos resultados da presente pesquisa se apóiam no enfoque da Ergonomia da Atividade (Guérin, Laville, Daniellou, Duraffourg \& Kerguellen, 2001; Laville, 1977). Essa disciplina pode ser conceituada como uma abordagem científica antropocêntrica que se fundamenta em conhecimentos interdisciplinares das ciências humanas para, de um lado, compatibilizar os produtos e as tecnologias com as características dos usuários e, de outro, humanizar o contexto sociotécnico de trabalho, adaptando-o tanto aos objetivos do sujeito e/ou grupo, quanto às exigências das tarefas.

No caso presente, o uso do referencial da Ergonomia da Atividade é restrito, pois se busca realizar uma reflexão de modelos do ser humano que se encontram subjacentes nas práticas de gestão de QVT, com base nas críticas à gestão do trabalho que nasceram dos achados desse referencial teóricometodológico. A relação entre Ergonomia da Atividade e o campo temático da QVT pode ser melhor compreendida em Ferreira (2008).

A abordagem metodológica da presente pesquisa, por sua vez, se inscreve na modalidade de estudo de caso (Goldenberg, 1997). Trata-se de uma investigação de natureza exploratória, sem a pretensão de buscar generalizações para as organizações públicas brasileiras. A perspectiva, em longo prazo, é construir bases empíricas para se construir uma agenda de pesquisa mais estruturada. A questão norteadora do processo de investigação consistiu, portanto, em responder como se caracteriza o perfil das práticas de QVT em órgãos públicos brasileiros.

\section{Método}

\section{Participantes}

A definição do grupo de gestores públicos que participaram da pesquisa foi precedida de um levantamento preliminar, via telefone, de todos os órgãos públicos federais que possuíam programas ou atividades de QVT. A indagação inicial consistia em saber se no órgão público havia um programa ou se este desenvolvia atividades de QVT, identificando-se 30 instituições dos três poderes da república (executivo, legislativo e judiciário). Dessa forma, constituíram o campo da pesquisa 10 órgãos públicos federais (dois do legislativo, três do judiciário e cinco do executivo), cuja escolha se deu com base na disponibilidade de tempo e do interesse de gestores em participarem da pesquisa. Assim, 13 gestores que desempenhavam a função de coordenadores ou integravam os "comitês" de QVT dos órgãos participaram da pesquisa.

O perfil dos participantes fornece informações para contextualizar os resultados obtidos: Gênero - dois homens e 11 mulheres; Idade - bastante variada, de 22 a 62 anos, com média de 42 anos; Escolaridade - todos com nível superior completo e oito deles com cursos de pós-graduação; Formação profissional - Pedagogia $(n=4)$, Administração de Empresas ( $n=3)$, Psicologia $(n=2)$, Direito $(n=1)$, Enfermagem $(n=1)$, Educação Física $(n=1)$, Ciências Contábeis $(\mathrm{n}=1)$; Tempo de trabalho no órgão - de 6 meses a 27 anos, média de 9 anos e 5 meses; Tempo de atuação em QVT de 1 a 10 anos, média de 3 anos (indicando que alguns dos participantes já tinham tido experiência na área, trabalhando em outras instituições).

\section{Instrumentos}

A coleta de dados se apoiou na: (a) análise de fontes documentais (missão, objetivos, estrutura organizacional) fornecidas pelos gestores dos órgãos públicos, com destaque para informações textuais existentes sobre QVT; e (b) realização de entrevistas semi-estruturadas (Martins \& Bicudo, 1994) construídas para avaliar os seguintes tópicos: conceito de QVT, política de QVT adotada pela instituição (caso houvesse), localização do programa ou atividades no organograma do órgão, avaliação das atividades desenvolvidas e fatores prejudiciais à QVT naquela instituição. $\mathrm{O}$ tempo médio de duração das entrevistas foi $1 \mathrm{~h} 20 \mathrm{~min}$, totalizando cerca de $12 \mathrm{~h}$.

\section{Procedimento}

A análise documental foi realizada com base na leitura do material disponibilizado pelos gestores (em geral, ao final das entrevistas, sob o formato, por exemplo, de folderes) e/ ou encontrados nos sítios dos órgãos públicos. $\mathrm{Na}$ análise documental, buscou-se identificar subsídios teóricos, metodológicos e técnicos que possibilitassem compreender como se caracterizavam as práticas gerenciais de QVT.

A realização das entrevistas durou cerca de um mês, conforme disponibilidade dos participantes. Duas pesquisadoras foram preparadas para conduzir as entrevistas. As duas primeiras entrevistas foram realizadas em parceria e, em seguida, foram objeto de discussão e avaliação a posteriori. As demais entrevistas $(n=8)$ foram realizadas individualmente pelas pesquisadoras.

A realização de cada entrevista foi conduzida com base nos seguintes passos: (a) informações iniciais (identificação da pesquisadora, objetivos, aspectos ontológicos); (b) apresentação do Termo de Informações Básicas e Consentimento e solicitação de assinatura do mesmo; (c) solicitação de autorização para gravação da entrevista em fita cassete; (d) formulação das questões centrais da pesquisa; e (e) levantamento do perfil do entrevistado (idade, gênero, formação, tempo de trabalho no órgão e em QVT). As fitas cassetes foram transcritas e desmagnetizadas no período de 15 dias após a realização da entrevista, conforme previsto no termo de consentimento.

\section{Análise de Dados}

Após transcrição das fitas, os dados de verbalização foram tratados com base na técnica de análise de conteúdo, proposta por Bardin (1977). Nesse sentido, buscou-se identificar categorias temáticas em cada uma das questões presentes na entrevista semi-estruturada, configurando os "núcleos de sentido" que compunham a fala dos entrevistados. A presen- 
ça ou frequência de tais núcleos forneceram elementos de respostas ao objeto da pesquisa.

De acordo com Bardin (1977), esse método de investigação não é apenas um conjunto de técnicas de análise das comunicações que utiliza procedimentos sistemáticos e objetivos para descrever conteúdo de mensagens. Mas tem, principalmente, a intenção de produzir inferências, recorrendo a indicadores, quantitativos ou não, de conhecimentos relativos às condições de produção (ou recepção) das mensagens.

Os dados obtidos na análise documental serviram de fonte complementar e acessória para a análise dos resultados advindos das entrevistas, contribuindo de forma importante para contextualizar o discurso dos gestores no campo da QVT. Em face do reduzido número de participantes e do volume restrito de informações coletadas não se utilizou tratamento estatístico nem o recurso de apresentação dos dados sob a forma de gráficos e figuras.

\section{Resultados}

A pergunta que norteou a coleta de dados da pesquisa buscou identificar como se caracterizavam as práticas de QVT em órgãos públicos federais. Os resultados apresentados a seguir contemplam seis categorias temáticas que, no conjunto, fornecem elementos de resposta ao objeto de investigação.

\section{Conceituação de QVT}

A primeira pergunta da pesquisa, desdobramento da questão central, consistiu em saber dos gestores entrevistados sobre os aspectos teóricos de QVT: do ponto de vista conceitual, o que é Qualidade de Vida no Trabalho?

Globalmente, os entrevistados demonstraram certa dificuldade em responder prontamente essa questão, obrigando os pesquisadores a enfatizarem qual era a definição de QVT que servia de suporte às atividades realizadas no órgão. $\mathrm{O}$ tratamento dos dados obtidos possibilitou identificar os seguintes eixos-temáticos na categoria "conceituação de QVT": (a) conceito amplo e complexo; (b) bem-estar integral do servidor; e (c) boa relação do servidor com o seu trabalho.

Duas verbalizações são representativas dessa categoria temática (grifos nossos):

É o trabalho do corpo, mente e espírito para [o servidor] se relacionar de maneira harmoniosa consigo mesmo e com os outros, contribuindo para a construção de um mundo melhor.

Qualidade de vida é tudo o que sai da rotina do trabalho, que sai da parte mecânica. Tudo o que possa fazer com que o servidor relaxe, venha mais disposto, mais preparado para o trabalho, trabalhe de forma mais satisfatória.

Em geral, constatou-se que o conceito de QVT entre os gestores se caracteriza pela (a) ausência propriamente dita de uma definição e (b) uma incipiente difusão entre os servido- res. Cabe registrar que apenas em uma instituição realizou-se um levantamento prévio sobre QVT entre os servidores.

\section{Política de gestão de QVT}

Quando indagados sobre se havia uma política de QVT no órgão, a primeira reação dos respondentes foi, tal qual a primeira questão, de dificuldade em responder, levando os pesquisadores a perguntarem se havia algum documento institucional (em termos de diagnóstico, objetivos, metas, avaliação) que orientasse a prática de QVT no órgão. Os dados possibilitaram identificar os seguintes eixos-temáticos: (a) diagnóstico incipiente da necessidade de QVT no órgão; (b) metas imprecisas, centradas na melhoria do desempenho dos servidores; e (c) abordagem metodológica indefinida.

Nessa categoria temática, dois excertos de entrevista são bastante representativos do que pensam os entrevistados sobre o assunto (grifos nossos):

Não foi feito um diagnóstico "do jeito que deveria ter sido feito". Foi mais especifico com os tipos de palestras (temas) que as pessoas gostariam que fossem abordados.

[Promover ações que levem à] redução do absenteísmo ..., aumento da produtividade, melhoria nas relações interpessoais e gerenciais, melhoria do ambiente de trabalho e redução do sedentarismo.

Constatou-se, de fato, a ausência predominante de uma política institucional claramente definida para conduzir as atividades de QVT nos órgãos. O diagnóstico do que precisa ser feito em QVT se caracteriza majoritariamente por "entrevistas" com chefias e consultas informais a poucos servidores. No cotidiano dessas organizações públicas, ações momentâneas, tópicas e pontuais (e.g., reeducação alimentar), são largamente implementadas sem uma abordagem metodológica rigorosa, sistemática e pertinente para o conjunto de atividades realizadas.

\section{Lócus organizacional das atividades em QVT}

Buscando identificar a importância institucional dada aos programas de QVT, perguntou-se onde se situava no organograma da instituição o "programa" ou atividades de QVT. Nesse caso, os dados coletados apontam claramente que o lócus organizacional de QVT nos órgãos públicos situa-se nas unidades administrativas com terminologias diversas (secretaria, diretoria, divisão, coordenação). Nesse sentido, a QVT aparece nitidamente vinculada às áreas de Recursos Humanos (sic), sobretudo, associada aos setores responsáveis por saúde, comportamento organizacional e competências.

\section{Tipos de atividades implementadas em QVT}

Nesse aspecto, os resultados obtidos são bastante interessantes e ilustrativos das práticas de QVT nos órgãos 
analisados. A Tabela 1 apresenta o tratamento taxonômico dos dados obtidos dos tipos de atividades desenvolvidas em QVT nos órgãos. Os resultados apresentados mostram a diversidade dos tipos de atividades que caracterizam as práticas de QVT nos órgãos e, sobretudo, a predominância de ações do tipo anti-estresse.

Alguns trechos de depoimentos dos gestores entrevistados são representativos nessa categoria temática (grifos nossos):

As ações de Qualidade de Vida são atividades que possibilitam a valorização do servidor como ser integral, contribuindo com seu bem-estar e potencializando seu desempenho na Casa.

As atividades ainda não são muito abrangentes porque as pessoas ainda não estão nem preparadas nem voltadas para isso. A gente está trabalhando o interesse de uma forma bem sutil..

Nós estamos levantando para vocês o que existe atualmente [aqui] que poderia ser chamado de ações de valorização e Qualidade de Vida no Trabalho. Porque nós observamos que o que os programas instituidos fazem é, praticamente, o que nós fazemos.

As atividades são, regra geral, as mesmas para todos servidores, independentemente do cargo, função ou tipo de tarefa que desempenhem. A exceção ficou por conta da ginástica laboral em apenas um órgão público, pois esta era feita em grupo, mas com exercícios específicos conforme a função do funcionário.

\section{Avaliação das atividades de QVT}

Nessa dimensão analítica das práticas de QVT nos órgãos públicos federais, identificou-se os seguintes eixos-temáticos: (a) avaliação das atividades isoladamente; (b) avaliações das atividades feitas por meio de questionários; e (c) avaliação informal com participantes.

Algumas verbalizações dos gestores ilustram de forma representativa o ponto de vista do grupo sobre essa temática (grifos nossos):

Qual foi o diferencial daquele servidor que começou a oficina para agora? É isso que estamos avaliando... como é a produtividade dessas pessoas.

Você conversa, pergunta o que eles querem, o que a gente pode melhorar... é sempre pela conversa [o método de avaliação].

Além desses aspectos, majoritariamente manifestos, constatou-se que em poucos órgãos são feitas avaliações globais das atividades de QVT. Residualmente, identificou-se que: (a) um órgão constituiu um grupo de trabalho específico para acompanhamento e controle das atividades; (b) outro avalia a parte logística, a qualidade da atividade desenvolvida, os relacionamentos interpessoais inter e intra-unidade, as relações hierárquicas, a comunicação organizacional com os servidores, o equipamento e o material disponível. Marginalmente, uma afirmação merece registro: "Sabe que essa é uma boa ideia?! Eu ainda não tinha pensado nisso. É uma ideia... fazer uma avaliação no final do ano das atividades". (grifos nossos)

\section{Fatores prejudiciais à QVT}

Quando perguntados sobre o que poderia ser prejudicial à QVT no órgão em questão, os gestores, majoritariamente, enfatizaram aspectos que deram origem nessa categoria aos seguintes eixos-temáticos: (a) cobrança e pressão sobre os funcionários; (b) intensa carga de trabalho; e (c) infra-estrutura deficiente (mobiliário, espaço, instalações inadequadas).

Tabela 1. Tipos de atividades de QVT $(\mathrm{N}=34)$ nos órgãos públicos federais.

\begin{tabular}{lll}
\hline Físico-Corporais & Eventos Coletivos & Suporte Psicossocial \\
\hline$\checkmark$ Academia & $\checkmark$ Apresentações artísticas dos servidores & $\checkmark$ Acolhimento das pessoas afastadas, em \\
$\checkmark$ Aikido & $\checkmark$ Campanhas assistenciais & reabilitação ou adaptação \\
$\checkmark$ Alongamento & $\checkmark$ Coral & $\checkmark$ Acompanhamento psicossocial \\
$\checkmark$ Atividades posturais & $\checkmark$ Feiras & $\checkmark$ Curso de pintura \\
$\checkmark$ Caminhada & $\checkmark$ Festas & $\checkmark$ Cursos de línguas \\
$\checkmark$ Capoeira & $\checkmark$ Palestras & $\checkmark$ Grupos de apoio \\
$\checkmark$ Dança de salão & $\checkmark$ Semana de Qualidade de Vida & $\checkmark$ Incentivo ao estudo \\
$\checkmark$ Ginástica laboral & $\checkmark$ Semana do Servidor & $\checkmark$ Inclusão digital \\
$\checkmark$ Ginástica localizada & $\checkmark$ Torneios e competições & $\checkmark$ Orientações e "ambientação" do servidor \\
$\checkmark$ Hidroginástica & & $\checkmark$ Preparação para a aposentadorituião \\
$\checkmark$ Jump fit & & $\checkmark$ Readaptação e reabilitação funcional \\
$\checkmark$ Medicina preventiva e saúde bucal & & \\
$\checkmark$ Natação & & \\
$\checkmark$ Reeducação alimentar &
\end{tabular}

Fonte: Sites dos órgãos e dados de entrevistas. 
Trechos dos depoimentos de alguns gestores, apresentados a seguir, são exemplos dessa categoria temática (grifos nossos):

A pressão acaba deixando o servidor muito estressado. Tem época que ele não vai mais pra ginástica porque acha que o chefe quer aquele serviço...

Os chefes acham que as pessoas têm que vir pra cá para trabalhar, não para se divertir.

Há um estresse por trabalhar na "vitrine" do país. Não se pode errar.

Eles [chefes] acham que pra trabalhar não pode rir.

Os resultados mostram também o sentido do trabalho como "coisa séria, que não pode ter prazer envolvido", colocando em primeiro plano um valor constitutivo da cultura organizacional. Para além dos aspectos relativos aos modelos de gestão existentes, os gestores também salientaram outros aspectos considerados como prejudiciais às atividades de QVT, tais como: falta de tempo dos servidores para participar das atividades oferecidas; carência de pessoal para desenvolver atividades; burocracia para realização de atividades, desconhecimento dos servidores sobre QVT; aceitação e/ou adesão dos coordenadores e chefes ao programa.

\section{Discussão}

No conjunto, os resultados obtidos traçam um perfil das práticas de gestão de QVT, conforme as informações prestadas pelos participantes da pesquisa. No caso estudado, parece prevalecer um enfoque gerencial de QVT incipiente e com baixo grau de coerência interna. Nesse contexto, a adoção de QVT se filia a uma perspectiva do senso comum e sugere um modismo, assim como se observou no "movimento de reengenharia" na década de 1990. Alguns aspectos merecem uma reflexão mais apurada.

O primeiro fato que chama a atenção é a dificuldade dos gestores em conceituarem QVT. Isso é compreensível, pois mesmo entre os teóricos da área não há consenso sobre o que vem a ser QVT do ponto de vista conceitual (Bom Sucesso, 2002; Signorini, 1999; Silva \& Marchi, 1997). Há, por exemplo, corrente que sustenta uma abordagem caso a caso, na qual cada programa tenha o seu conceito e visão de QVT. Entretanto, é fundamental que o processo de gestão se apóie em bases teóricas, metodológicas e éticas mais sólidas. Nesse caso, a expectativa dos pesquisadores era que os gestores ao menos afirmassem qual era o referencial teórico adotado. A questão conceitual é um dos fatores críticos para o desenvolvimento de competência em QVT, conforme enfatiza Limongi-França (2004). Uma análise das tentativas de conceituação pelos entrevistados coloca em primeiro plano a ênfase de QVT na dimensão do indivíduo, sobretudo, como tarefa de cada servidor público. Nessa perspectiva, QVT só pode ser alcançada como obra individual. É, como afirma um participante da pesquisa, "o uso do corpo, mente e espirito para se relacionar de maneira harmoniosa consigo mesmo e com os outros". Aqui, a responsabilidade institucional desaparece e o trabalhador se transforma em variável de ajuste, ou seja, é transferida para ele a responsabilidade pela promoção da QVT (Abrahão, 2000; Daniellou, Laville \& Teiger, 1989). Ou melhor, a responsabilidade institucional consiste apenas em disponibilizar atividades que alterem a rotina de trabalho, visando o relaxamento e o aumento da disposição de cada um para trabalhar de forma mais satisfatória. Os resultados globais da investigação mostram que as atividades de QVT são realizadas buscando-se garantir a produtividade como meta central; a questão do bem-estar ocupa plano secundário no discurso dos participantes.

Merece destaque também o traço marcante nos resultados de não haver uma política institucional para QVT nos órgãos públicos. Nessa esfera, procedimentos improvisados e assistemáticos predominam nas práticas gerenciais de QVT. A ausência, por exemplo, de descrição de cenários, objetivos, metas, recursos instrumentais e método de avaliação como alguns dos elementos que caracterizam a formulação de uma política impacta negativamente na qualidade do processo de gestão de QVT. A implantação de um PQVT deve estar ancorada em uma formulação clara de política de QVT que, ao menos, explicite o conceito, as diretrizes, a estrutura organizacional necessária. Assim, a falta de política parece colocar os gestores em sérias dificuldades, pois não havendo, por exemplo, um método de avaliação das atividades de QVT, como saber se a tão desejada produtividade foi efetivamente alcançada? No tocante ao aspecto "avaliação das atividades de QVT", os resultados apenas corroboram o aspecto crítico da falta de política, pois avaliações isoladas e de natureza informal reforçam o trato incipiente na gestão de QVT.

Quanto ao lócus organizacional das atividades em QVT, o fato de a temática situar-se majoritariamente nas unidades administrativas (secretaria, diretoria, divisão, coordenação) parece reforçar uma perspectiva reducionista na abordagem de QVT. Nesse caso, fortalece-se a compreensão de que esse tema é quase que uma "exclusividade" dos profissionais que atuam nas áreas de saúde, administração e comportamento organizacional. Acredita-se que tais profissionais têm um papel relevante no campo de gestão de QVT. Não se trata de negar tal importância. A questão que se coloca é: em que medida tal perspectiva reforça uma cultura organizacional em que a QVT é considerada uma tarefa de especialista, portanto, missão de poucos? Tal enfoque é bastante limitado e tende a produzir impactos negativos para a própria gestão de QVT pelo não envolvimento efetivo de outros atores e setores da organização.

Os resultados que mais respondem à questão central da pesquisa dizem respeito aos tipos de atividades implementadas em QVT. Nesse caso, torna-se visível o que realmente se faz, ou seja, o núcleo central das práticas de QVT nos órgão públicos, quais sejam: atividades físico-corporais. $\mathrm{O}$ cardápio de ações é diversificado, englobando atividades físico-corporais (e.g., dança de salão), coletivas (e.g., coral) e suporte psicossocial (e.g., grupos de apoio). Tudo isso é feito, como afirmam alguns entrevistados, em nome da valorização do servidor como ser integral para "potencializar seu desempenho na casa". Atividades que são, regra geral, feitas de forma padronizada, não se levando em conta 
cargo, função ou tipo de tarefa desempenhada pelo servidor público. O paradigma da padronização (the one best way) de feição taylorista está aqui também presente, deixando os aspectos de diversidade e de variabilidade intra e interindividual em plano secundário (Laville, 1977; Wisner, 1994). Não há problema com a existência em si de tais atividades (consideradas anti-estresse) nas organizações. Mas, restringir as práticas de QVT a apenas essa esfera, certamente põe em relevo uma visão assistencial de QVT, de natureza compensatória e paliativa. As causas institucionais do estresse, do desgaste, da fadiga (e.g., condições pouco adequadas de trabalho) permanecem intocadas. Reaparece com toda força a noção do indivíduo como variável de ajuste para a solução de problemas que não foram por ele produzidos (Ferreira, 2006b). Nessa ótica, as práticas de QVT buscam, efetivamente, aumentar a resistência dos trabalhadores para continuar habitando um ambiente adverso de trabalho.

Os resultados relativos aos fatores prejudiciais à QVT, existentes nos órgãos públicos, têm uma importância fundamental para esta pesquisa. Eles colocam em primeiro plano o paradoxo que serve de título ao presente texto: o descompasso entre problemas e práticas gerenciais em QVT. Nesse caso, cabe a pergunta: se os fatores críticos, prejudiciais para QVT, aqueles que são fontes de problemas para os servidores públicos, dizem respeito à cobrança e pressão sobre os funcionários, a intensa carga de trabalho e a infra-estrutura deficiente, por que, então, as práticas de gestão de QVT estão focadas em atividades anti-estresse? Não seria mais coerente, desejável e pertinente agir nas causas do estresse e não exclusivamente em seus efeitos? O caráter ideológico, nesse caso, transita da aparência para a essência: as práticas de gestão se inscrevem numa perspectiva obstinada em garantir desempenho satisfatório dos servidores a qualquer preço. A ideia do trabalho como "coisa séria, que não pode ter prazer envolvido", conforme ilustra um trecho de verbalização de um entrevistado, é apenas um aspecto dessa perspectiva ideológica. Certamente, identifica-se aqui um dos problemas mais críticos dos PQVTs. Em muitas organizações, a adesão tende a ser baixa e a participação dos trabalhadores nesses programas logo se transforma em curva declinante, conforme se queixam muitos gestores.

\section{Considerações Finais}

A presente pesquisa ensejou algumas reflexões que possibilitaram identificar suas principais mensagens. Para melhor contextualizá-las, faz-se pertinente retomar a pergunta central da pesquisa: como se caracterizam as práticas de QVT em órgãos públicos federais? Nesse sentido, a principal mensagem da pesquisa é nítida: a gestão de QVT no serviço público federal investigado se caracteriza pelo descompasso entre os problemas existentes e as práticas gerenciais. Além disso, toda produção científica importante sobre o tema, mencionada na introdução, encontra-se ausente nos relatos dos gestores. Três aspectos se sobressaíram, além dos problemas que foram identificados:

\section{As práticas gerenciais de QVT têm como foco o indivíduo.}

Ele, o servidor, é a "peça” organizacional de ajuste. Uma espécie de parafuso a ser ajustado para que a engrenagem (a organização) gere os frutos esperados e cumpra a sua missão institucional. Tal perspectiva tem sintonia com o paradigma da flexibilidade, cada vez mais em voga em tempos de reestruturação produtiva, cujo caráter ideológico é apontado por Sennett (2001). Escreveu ele (grifos nossos):

\begin{abstract}
A palavra 'flexibilidade' entrou na língua inglesa no século quinze. Seu sentido derivou originalmente da simples observação de que, embora a árvore se dobrasse ao vento, seus galhos sempre voltavam à posição normal. 'Flexibilidade' designa essa capacidade de ceder e recuperar-se da árvore, o teste e restauração de sua forma. Em termos ideais, o comportamento humano flexivel deve ter a mesma força tênsil: ser adaptável às circunstâncias variáveis, mas não quebrado por elas. A sociedade hoje busca meios de destruir os males da rotina com a criação de instituições mais flexíveis. As práticas de flexibilidade, porém, concentram-se mais nas forças que dobram as pessoas. (p. 53)
\end{abstract}

\section{As atividades que integram as práticas de gestão em QVT são de natureza assistencial.}

Tais atividades são, como mencionado, válidas em si mesmas. Mas, tendem a se tornar esforços estéreis na medida em que se distanciam dos problemas efetivos que comprometem o bem-estar dos servidores públicos. Nesse sentido, elas têm fortemente um caráter compensatório do desgaste vivenciado pelos servidores públicos e, ainda que sem pretender, reivindicam um papel de "medicamento que cura os males do trabalho".

\section{As práticas de gestão preconizam o bem-estar de modo acessório, a ênfase é na produtividade.}

A perspectiva é garantir a realização das tarefas prescritas. Aqui se constata um enfoque recorrente de conceber as agências de Estado como se fossem empresas privadas. Lógico que, no serviço público deve haver preocupação com a produtividade, os resultados, as metas etc. Até porque "ser produtivo" é uma das dimensões fundantes do sentido do trabalho, um modo de exercício da felicidade. Mas, setor público e setor privado, mesmo no contexto de uma sociedade capitalista, têm distinções fundamentais que delineiam perfis de cultura organizacional singulares. Exportar ou importar modelos de modo acrítico, sem considerar tais singularidades é aumentar as chances do insucesso na gestão de QVT. Nesse cenário, os modelos de gestão do trabalho são objetos inquestionáveis, temas tabus nas organizações.

As reflexões geradas pela pesquisa possibilitaram também pensar em uma agenda de trabalho que articule preocupações acadêmicas e organizacionais. Um tópico dessa agenda consiste no desafio de se contrapor a uma perspectiva hegemônica de QVT assistencialista para constituir as bases de 
uma abordagem de QVT de natureza preventiva (Ferreira, 2006a). A ótica em QVT preventiva impõe ter como foco a remoção de indicadores críticos que geram mal-estar nos contextos de produção. Para tanto, é necessário atuar em três dimensões interdependentes: nas condições, na organização e nas relações sociais de trabalho (Mendes \& Ferreira, 2004). Além disso é crucial conceber QVT como uma tarefa de todos (e não uma responsabilidade exclusivamente individual) e uma busca permanente de harmonia entre o bem-estar, a eficiência e a eficácia nos ambientes organizacionais (e não no foco exclusivo da produtividade). Dentro de uma perspectiva aplicada, alguns requisitos se colocam como estratégicos para operacionalizar a abordagem de QVT preventiva, a saber:

a) Mudança da mentalidade que preside os modelos de gestão do trabalho, ou seja, novas práticas em QVT necessitam que os protagonistas organizacionais removam valores, crenças e concepções, muitas vezes petrificados, que podem estar na origem dos obstáculos para a QVT. A premissa é clara, mudança de mentalidade implica em "pensar diferentemente para agir diferentemente". Não se mudam práticas, de forma consequente, sem mudança de consciência;

b) Indissociabilidade entre produtividade e bem-estar significa resgatar o papel ontológico do trabalho como um vetor histórico de construção da identidade individual e coletiva. A indissociabilidade implica em conceber produtividade na sua acepção positiva, ou seja, um meio de exercício do bem-estar;

c) A prática de QVT deve se apoiar em um modelo antropocêntrico de gestão do trabalho que, entre outras tarefas, preconize: valorizar os trabalhadores como principais protagonistas dos resultados, promover o reconhecimento individual e coletivo, estimular a criatividade e a autonomia na execução de tarefas, proporcionar o desenvolvimento pessoal e coletivo com base na cooperação intra e intergrupal e possibilitar a participação efetiva, principalmente, nas decisões que afetem o bem-estar individual e coletivo;

d) A implementação de QVT requer uma política de comunicação que dissemine, estimule e consolide uma cultura organizacional centrada em valores, crenças e ideias voltadas para o bem-estar individual e coletivo, dando visibilidade para práticas bem sucedidas, bem como promovendo a reflexão coletiva dos problemas existentes que comprometem a QVT;

e) A implantação de um programa de QVT não deve ser uma medida tópica, isolada e circunscrita a uma fração do organograma da organização. Ela deve ser transversal a toda estrutura organizacional e conduzida com base em uma sinergia organizacional que implique efetivamente no compromisso de dirigentes e gestores, cooperação interdisciplinar de todos especialistas envolvidos e, sobretudo, parcerias intersetoriais e sindicais.

Tais requisitos não podem ser compreendidos como uma panaceia capaz de resolver todos os problemas. A perspectiva é tê-los como pressupostos que podem ajudar o processo de implantação de PQVTs em bases mais sólidas. Tal perspectiva se propõe a resgatar o nexo entre as condições-organizaçãorelações socioprofissionais e as vivências de bem-estar e mal-estar no trabalho, bem como os riscos para a saúde dos trabalhadores e a satisfação de usuários, clientes e consumidores.
Os resultados da pesquisa não autorizam uma generalização para o setor público de um modo geral, sobretudo, em face do universo restrito de participantes e de órgãos que serviram para coleta de dados. Mas, pelas suas peculiaridades, tais resultados podem ser um caso ilustrativo de gestão de QVT no setor público. Uma pergunta poderá guiar investigações futuras: o descompasso entre problemas organizacionais existentes e práticas gerenciais de QVT se constitui, na atualidade, em uma tendência nos órgãos públicos?

Para além dos limites, possibilidades e desafios que nasceram desta investigação sobre as práticas de gestão de QVT no setor público federal, cabe uma reflexão adicional sobre o papel dominante que permanece reservado à díade indivíduo-trabalho na sociedade atual. As vivências de sentimento duradouro de desamparo, como exemplifica pesquisa nacional com auditores-fiscais da Previdência Social brasileira (Ferreira \& Mendes, 2003), mostram o sentido empobrecido que o trabalho pode assumir, ilustrado nas falas destes servidores públicos federais: "Sonhei com este cargo público. É verdade que ele me dá estabilidade e uma relativa segurança financeira. Mas, hoje, ele me emburrece, me rouba a felicidade".

\section{Referências}

Abrahão, J. I. (2000). Reestruturação produtiva e variabilidade do trabalho: uma abordagem da ergonomia. Psicologia: Teoria e Pesquisa, 16, 49-54.

Bardin, L. (1977). Análise de conteúdo. Lisboa: Edições 70.

Baumgarten, M. (2002). Reestruturação produtiva e industrial. Em A. D. Cattani (Org.), Dicionário crítico sobre trabalho e tecnologia (pp. 268-271). Porto Alegre: Editora da UFRGS.

Bom Sucesso, E. P. (2002). Relações interpessoais e qualidade de vida no trabalho. Rio de Janeiro: QualityMark.

Daniellou, F., Laville, A., \& Teiger, C. (1989). Ficção e realidade do trabalho operário. Revista Brasileira de Saúde Ocupacional, 17(68), 7-13.

Fernandes, E. (1996). Qualidade de vida no trabalho: como medir para melhorar. Salvador: Casa da Qualidade.

Ferreira, M. C. (2006a). Qualidade de vida no trabalho. Em A. D. Cattani \& L. Holzmann (Orgs.), Dicionário: trabalho e tecnologia (pp. 219-222). Porto Alegre: Editora da UFRGS.

Ferreira, M. C. (2006b). Ofurô corporativo. Retirado em 19/10/2009, de http://www.unb.br/noticias/unbagencia/artigo. php?id=202

Ferreira, M. C. (2008). A ergonomia da atividade se interessa pela qualidade de vida no trabalho? Reflexões empíricas e teóricas. Cadernos de Psicologia Social do Trabalho, 11, 83-99.

Ferreira, M. C., \& Mendes, A. M. (2003). Trabalho e riscos de adoecimento: o caso dos auditores-fiscais da Previdencia Social brasileira. Brasília: Edições Ler, Pensar, Agir (LPA).

Goldenberg, M. (1997). A arte de pesquisar: como fazer pesquisa qualitativa em ciências sociais. Rio de Janeiro: Record.

Guérin, F., Laville, A., Daniellou, F., Durrafourg, J., \& Kerguellen, A. (2001). Compreender o trabalho para transformá-lo: a prática da Ergonomia. São Paulo: Editora Edgard Blücher.

Hackman, J. R., \& Oldham, G. R. (1975). Development of the Job Diagnostic Survey. Journal of Applied Psychology, 2, 159-70. 
Laschinger, H. K. S., Finegan, J., Shamian, J., \& Almost, J. (2001). Testing Karasek's Demands-Control model in restructured healthcare settings: Effects of job strain on staff nurses' quality of work life. Journal of Nursing Administration, 31, 233-243.

Lau, R. S. M. (2000). Quality of work life and performance - An ad hoc investigation of two key elements in the service profit chain model. International Journal of Service Industry Management, 11, 422-437.

Laville, A. (1977). Ergonomia. São Paulo: USP.

Limongi-França, A. C. (2004). Qualidade de vida no trabalho: conceitos e práticas nas empresas da sociedade pós-industrial ( $2^{\mathrm{a}}$ ed.). São Paulo: Atlas.

Macedo, K. B. (2004). Qualidade de vida no trabalho: o olhar da psicologia e da administração. Goiânia: UCG.

Martel, J. P., \& Dupuis, G. (2006). Quality of work life: Theoretical and methodological problems, and presentation of a new model and measuring instrument. Social Indicators Research, 77, 333-368.

Martins, J., \& Bicudo, M. A. V. A. (1994). A pesquisa qualitativa em psicologia: fundamentos e recursos básicos ( $2^{\mathrm{a}}$ ed.). São Paulo: Moraes.

May, B. E. A. (1999). Longitudinal study of quality of work life and business. South Dakota Business Review, 58, 1-5.

Mendes, A. M., \& Ferreira, M. C. (2004). Gestão de pessoas focada na qualidade de vida no trabalho: bem-estar, uma tarefa de todos. Em Banco Central do Brasil (Org.), Anais do $1^{\circ}$ Fórum de Qualidade de Vida: trabalhando e vivendo com qualidade (pp. 3-8). Brasília: BC.

Sampaio, J. R. (2004). Qualidade de vida no trabalho e psicologia social. São Paulo: Casa do Psicólogo.
Sennett, R. (2001). A corrosão do caráter: consequências pessoais do trabalho no novo capitalismo. Rio de Janeiro: Record.

Signorini, M. (1999). Qualidade de vida no trabalho. Rio de Janeiro: Taba Cultural.

Silva, M. A. D., \& Marchi, R. (1997). Saúde e qualidade de vida no trabalho. Rio de Janeiro: Best Seller.

Sirgy, M. J., Efraty, D., Siegel, P., \& Lee, D. (2001). A new measure of Quality of Work Life (QWL) based on Need Satisfaction and Spillover theories. Journal Social Indicators Research, 55, 241-302.

Tuuli, P., \& Karisalmi, S. (1999). Impact of working life quality on burnout. Experimental Aging Research, 25, 441-449.

Walton, R. E. (1973). Quality of Work Life: What is it?. Sloan Management Review, 1, 11-21.

Westley, W. A. (1979). Problems and solutions in the quality of working life. Human Relations, 2, 113-123.

Wisner, A. (1994). A inteligência no trabalho: textos selecionados de ergonomia. São Paulo: Ministério do Trabalho MT / Fundacentro. 